\title{
Analysis of Lecturers and Employees Working Behavior Changing Against the Implementation of Safety Engineering and Environmental Health in Faculty of Engineering USU
}

\author{
Buchari $^{1}$, Nismah Panjaitan ${ }^{2}$, Doli M. Jabbar Dalimunthe ${ }^{3}$ \\ 1, 2, 3 Industrial Engineering, University of Sumatera Utara, Indonesia \\ ibosssanti@yahoo.com \\ nismahpjtegmail.com \\ JabbarDalimunthe@gmail.com
}

\begin{abstract}
One of the factors that causes of accidents due to the working risk on any production or business activities as well as Higher Education institutions is the human factor that more likely caused by the knowledge, attitudes and actions (behavior) of bad workers. There is still none data related to the implementation of occupational safety and health in the university environment that will be the main reason for the implementation of this study. The study started by identifying potential hazards that exist in the offices, classrooms and laboratory space in every department of the Faculty of Engineering in USU. The next step is to analyze the changes in the behavior of lecturer and employees by using $t$ test to see the extent of occupational safety and health training will affect lecturer and employee behavioral changing. From the results, the types of potential hazards are in the office, classroom and laboratory room is an electrical hazard of ergonomics danger, danger of noise, danger of falling, falling objects, thrown objects, and the scrap danger, mechanical danger, danger of fire and chemical hazard. From the $t$ test results showed that the value of the probability $p(0.000)<0.05$. This means that there are significant differences on the knowledge, attitudes and their actions of the lecturer and staff before and after the occupational safety and health (K3) training. It is necessary to design Occupational Safety and Health engineering in form of safety signs and procedures book as information in an attempt to prevent the accidents. From the results, the type of potential hazards are in the office space is a danger of electrical amounted to $26 \%$ of all types of hazards, while the potential hazards in the classroom is the danger of noise by $22 \%$ of the total types of hazards and potential hazards in the laboratory is a danger of electrical amounted $19 \%$ of the total of danger. Results of hazard identification obtained will be the input for the engineering safety and health with creating signs and book procedures for Health and Safety (K3) as information in an effort to prevent accidents, and are advised to attend the training of occupational safety and health (K3).
\end{abstract}

Keywords - Occupational Health and Safety (OHS), Behavioral, Engineering, Hazard, Behavior

\section{INTRODUCTION}

Work behavior is quite common among employees in many organizations, but much of it apparently goes unnoticed, unreported, or both [1], friends, family members, doulas, midwives, or nurses can provide this support [2]. Sometimes some of employee didn't have good work behavior and it can influence their healthy. Healthiness is not only refraining from diseases, it is also physical, mental, and social well-being according to the World Health Organization (WHO)[3]. Organizational culture and organizational structure are interrelated with safety and healthiness[4]. Occupational health with a fundamental approach of preventive medicine is a field where activities aiming at definition of health problems and protection of workers' health during work life take place [5]. Despite the implementation of many occupational safety and health (OSH) management practices, accidents at work still occur. From one perspective, this seems natural, as accidents are inherent to any activity, and comprehensive control of all of the hazards that may exist in any given organisation is impossible [6].That's why safty and healthy very influence with work behavior, that are presented with a problem in that how risks are perceived affects how they are managed with an ultimate effect on the organizational safety performance [7]. Occupational health and safety (OHS) management concerns the improvement in health conditions at workplace and reducing a sort of costs emanating from work accidents that could be originated by inadequate working environment, insufficient informing and low consciousness level of employees or lack of attention [8]. The number of occupational diseases and accidents has increased in parallel with the improvement in industry. A number of people died 
or maimed due to occupational diseases or accidents, $98 \%$ of which could be prevented[9]. The identification of potential areas of consensus and level of key national actors' engagement achieved, show the potentialities of adopting a knowledge based and inclusive approach to policy-making to address the issue of prevention and management of health and safety risks related to technological innovation within a framework of scientific uncertainty [10]. To see the occupational deseas need to know the hazard and nee to identification, There are two fundamental classes of complementary hazard identification methods, namely the function-driven class and the componentdriven class. In the first class, the design intention deviations are considered and then traced back to component failures. For the second class, component failures are traced to functional changes [11]. Hazard awareness is a skill that is more dominant in realtime hazard identification [12]. Management development the systematic approach to $\mathrm{OSH}$ management is not effective enough in terms of building the resilience or safety levels in an enterprise [13]. Therefore, safety program is needed and the safety performance of process industries must continue to improve [14]. To improve it, there are some option, like make training, make a program or change the management system [15]. OHS training in high instutuion especially in univerysity is minim, a few of traning which implemented in high institution. Engineering departement of USU consist of 7 deparment such as industrial, civil, electrical, mechanical, chemical, enviromental engineering and architecture. Every department of having chairman of the department of, secretary, civil servants and lecturer in the performance of any activity on a university campus good administration affairs and activities lecture. The good condition rooms of are critical to the performance of workers in activity in the room work. On the implementation of their jobs every day workers in an office every department of engineering faculty USU will is exposed to the risk of harm at work. A number of things interest on SHE in of the department of engineering faculty USU is a system lighting, air ventilation, construction and its equipment and operational to fire incident, cleanliness levels and sanitation, the use of the window when ac turn off, arrangement electricity installation, control against noise of the neighborhood, cleanliness work environment of a pile of a file and indeed in workspace, a means of communication, the use of computers, resting place workers, a depository file or files important and display-display every department in of engineering faculty USU.

This study will identify the potential danger by job safety analysis, know the chairman of the department of behavior, the department secretary, employees and lecturers engineering faculty usu about work safety and health, before done training work safety and health with pre test, know the chairman of the department of behavior, the department secretary, employees and lecturers engineering faculty USU about work safety and health through training work safety and health with the post test and he knows chairman of the department of behavior change, the department secretary, employees and lecturers engineering faculty USU training work safety and health by $t$ test. The results of the study is expected to be input, so that it can be produced procedure work safety and health a reference in activities in engineering faculty USU and an evaluation tool to identify occupational safety to majors in engineering faculty USU.

\section{RESEARCH METHOD}

Research object observed is the respondents who become a source of information regarding the needs of lab data. An object which has been used for respondents is the head of the department, the department secretary, civil servants and lecturers of engineering faculty USU. This research take palce in engineering departement of USU. This research is designed to be implemented for 1 year. In this study, data collection techniques used is observation techniques, survey techniques, interview and lietarure study. In figure 1 . the fish bone of this research.

Research carried out by performing a library research, the initial survey and preparing a research proposal, preparation of modules, designing training materials as well as designing questionnaires, conducting the training and the preparation of occupational health and safety procedures. This study will be carried out during the first year. 
The object of research is observed respondents as sources of information about the needs of the research data. Objects that are used as the respondent is Chair of the Department, Secretary of the Department, Employee and Lecturer at the Faculty of Engineering USU.

Methods of data collection in this study are:

1) Observation Techniques, namely direct field observation techniques regarding the activities of each department in the Faculty of Engineering USU before and after training of occupational safety and health (K3).

2) Technical survey, which is an activity survey using open and closed questionnaires were conducted before and after the implementation of occupational safety and health training (pretest and posttest).

3) Interview techniques, namely activities for collecting data by interviewing the Chairman of the Department, Secretary of the Department, Employee and Lecturer at the Faculty of Engineering USU.

4) Study of literature, which is an activity for studying the books and journals relating to occupational safety and health (K3).

\section{RESULT AND DISCUSSION}

\section{A. Hazard Identification}

The first step to be implemented in the research is hazard identification. This procedure started by observing the/ activity held in laboratory. Then followed by analyzing any activity is there containing danger or eksposed to potential danger. In each departments will be counted the chance to weighting against the state departments.

The potensial hazard in office of industrial engineering department will shown in figure 1.

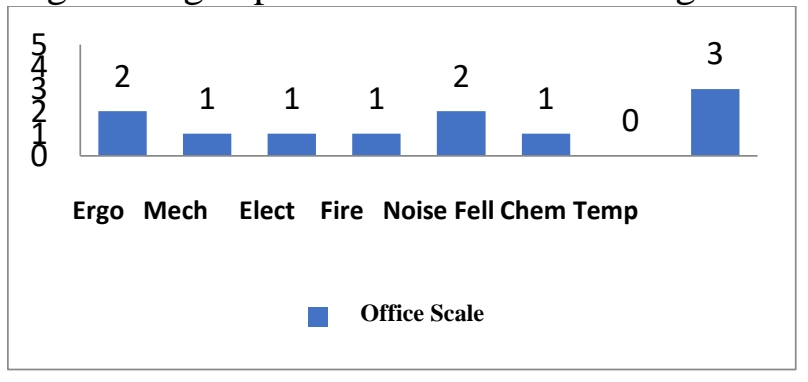

Fig. 1 Potensial Danger in Department of Industrial Engineering

Potential danger in office space department of industrial engineering is obtained a kind of danger that have value the highest is the type danger ergonomics be on the value 2 that is having 2 error posture.

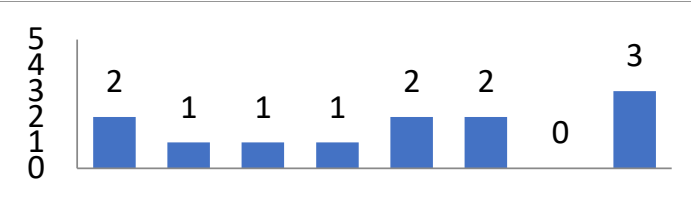

Ergo Mech Elect Fire Noise Fell Chem Temp

Office Scale

Fig. 2 Potential Danger In Department of Electrical Engineering

From the figure, ergonomic is the most potential danger in electrical engineering department.

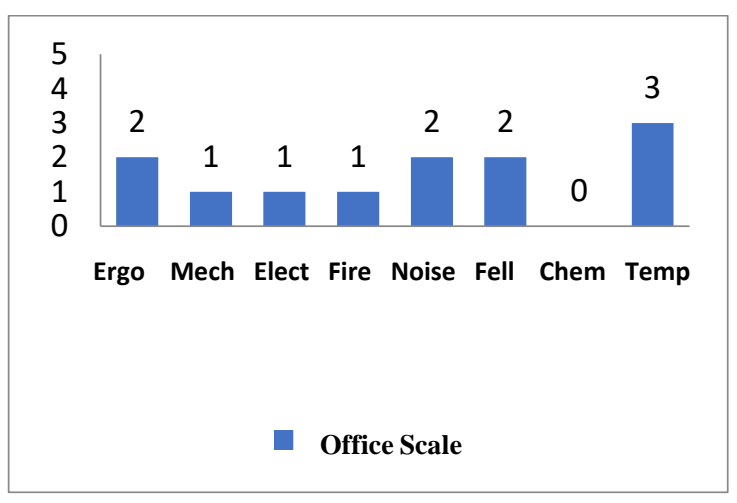

Fig. 3 Potential Danger In Department of Mechanical Engineering

From the figure, ergonomic is the most potential danger in machanical engineering department.

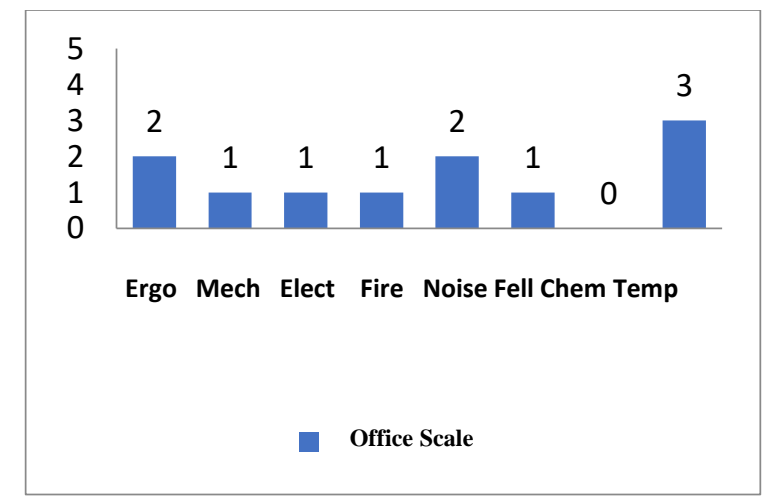

Fig 4. Potential Danger In Department of Chemical Engineering

From the figure, ergonomic is the most potential danger in machanical engineering department. 


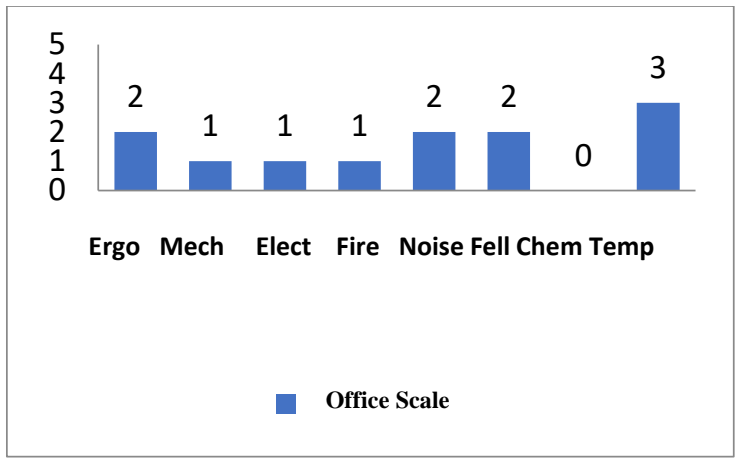

Fig 5. Potential Danger In Department of Enviromental Engineering

From the figure, ergonomic is the most potential danger in enviromental engineering department.

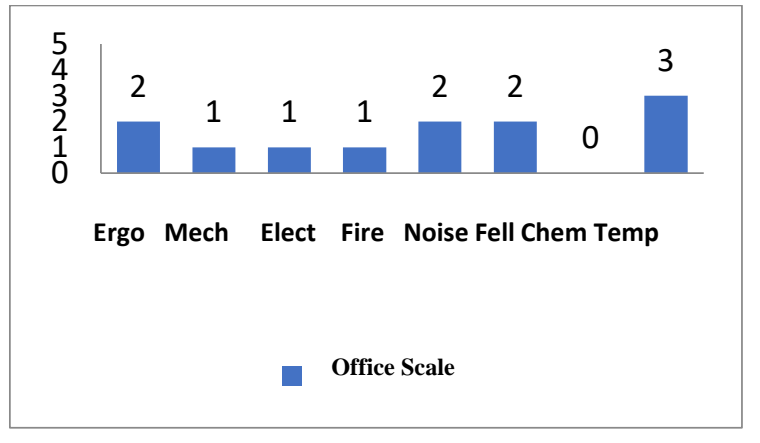

Fig 6. Potential Danger In Department of Civil Engineering

From the figure, ergonomic is the most potential danger in civil engineering department.

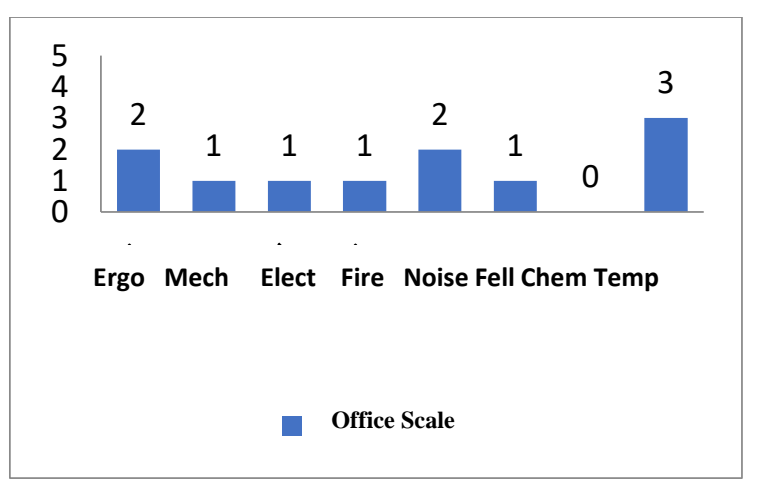

Fig 7. Potential Danger In Department of Architecture Engineering

From the figure, ergonomic is the most potential danger in architecture engineering department. The potensial hazard in laboratory of each department will shown in figure 8 until figure 14.

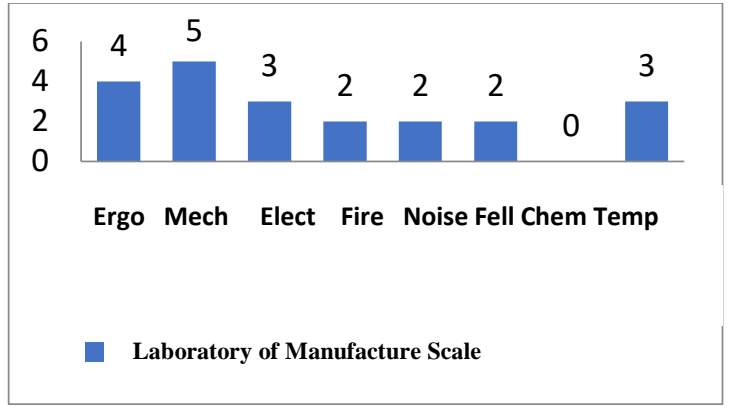

Fig 8. Potensial Danger in Department of Industrial Engineering

From the figure, mechanics is the most potential danger in laboratory of manufacturing of industrial engineering department.

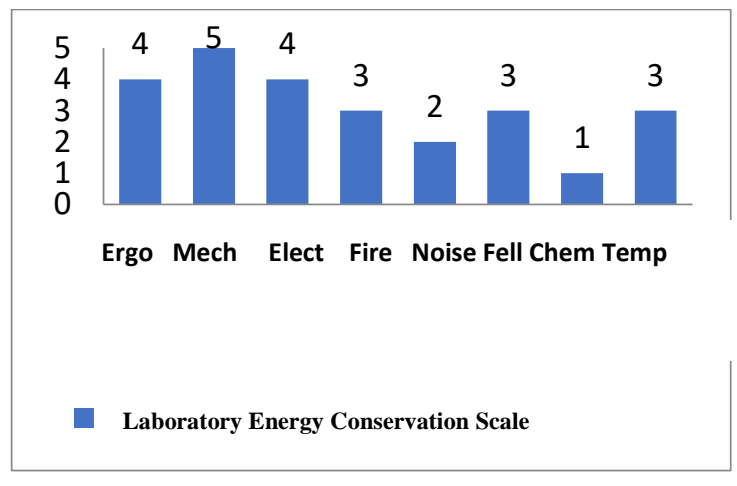

Fig 9. Potensial Danger in Department of Electrical Engineering

From the figure, mechanical and electrical is the most potential danger in laboratory of energy conservation of electrical engineering department.

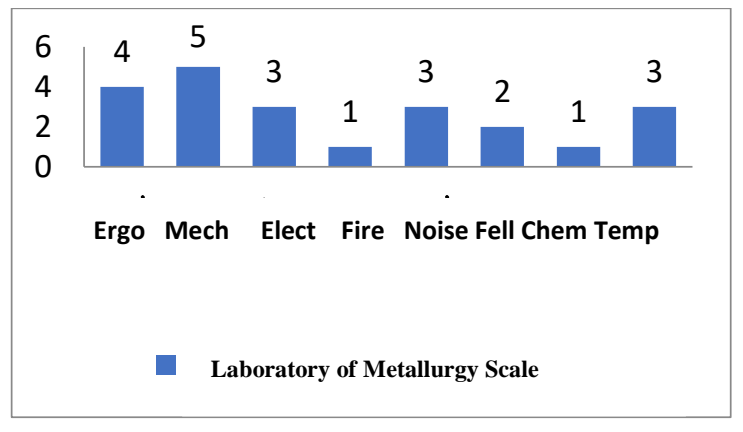

Fig 10. Potensial Danger in Department of Mechanical Engineering

From the figure, ergonomic and mechanics is the most potential danger in laboratory metallurgy of mechanical engineering department. 


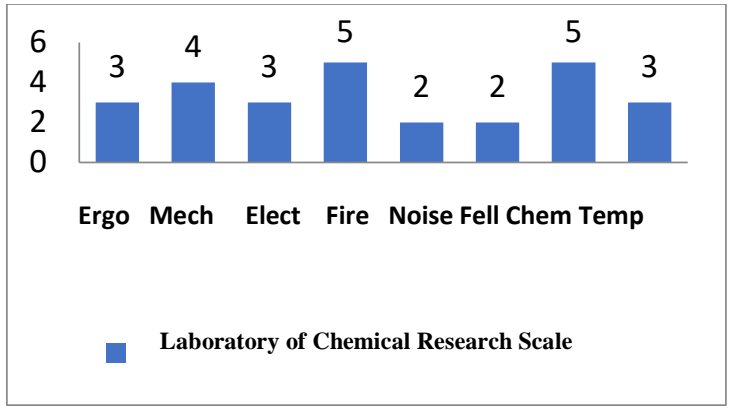

Fig 11. Potensial Danger in Department of Chemical Engineering

From the figure, ergonomic, fire and chemical is the most potential danger in laboratory of chemical research of chemical engineering department.

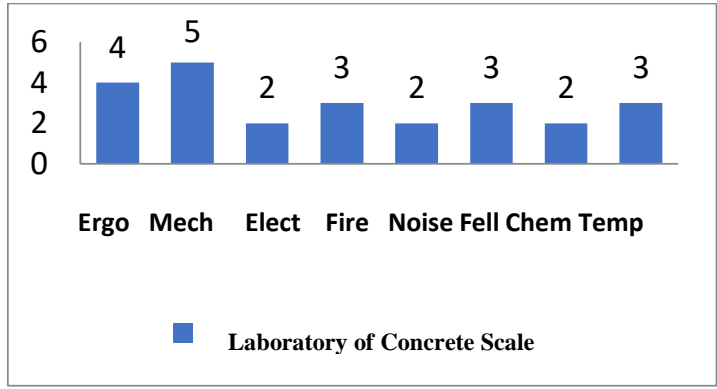

Fig 12. Potensial Danger in Department of Civil Engineering

From the figure, mechanic is the most potential danger in laboratory of concrete of civil engineering department.

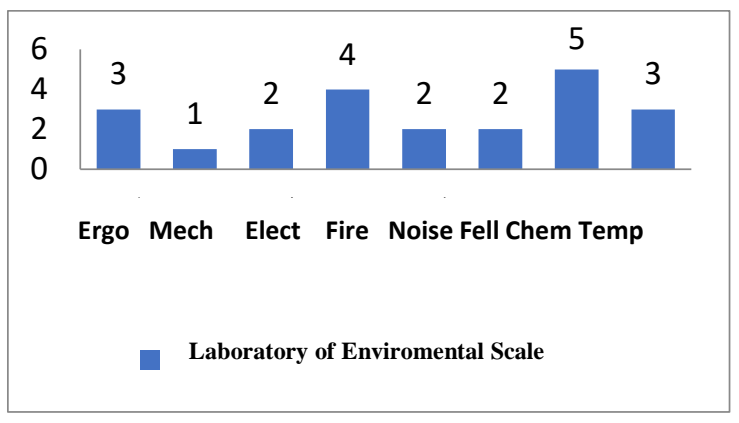

Fig 13. Potensial Danger in Department of Enviromental Engineering

From the figure, chemical and fire is the most potential danger in laboratory of enviromental of environmental engineering department.

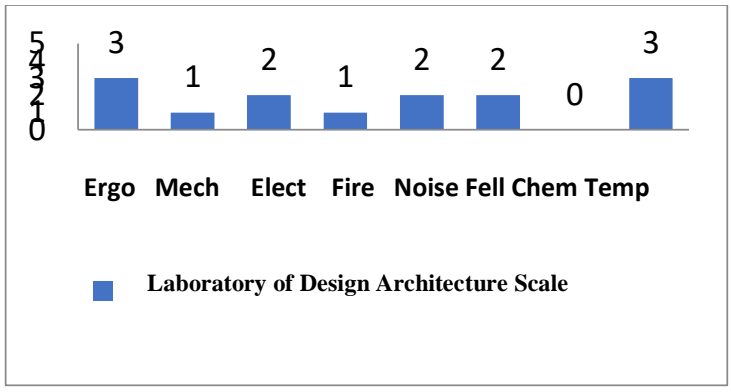

Fig 14. Potensial Danger in Department of Architecture

From the figure, mechanical and electrical is the most potential danger in laboratory of design architecture of architecture department.

\section{B. The Influence of Training Work Safety and Health \\ 1) The Influence of Occupational Health and Safety Training to Knowledge}

The data analysis done to see the effects of occupational health and safety training (K3) to knowledge, attitudes and actions of teachers and employees of the Faculty of engineering. The analysis was done by looking at the difference by giving a pretest and posttest questionnaires with $t$ test using SPSS 22.

Test results $t$ to knowledge part of safety and healthy common obtained value sig .(2-tailed ) as much as $0,000<0.05$, because the value of sig . (2tailed ) smaller of the value of 0.05 so can be concluded that there are differences significantly between knowledge of safety and healthy common respondents before and after training work safety and health.

This can also be seen on the figure 15 the following which indicates the presence of increased knowledge about safety and health common respondents before and after training.

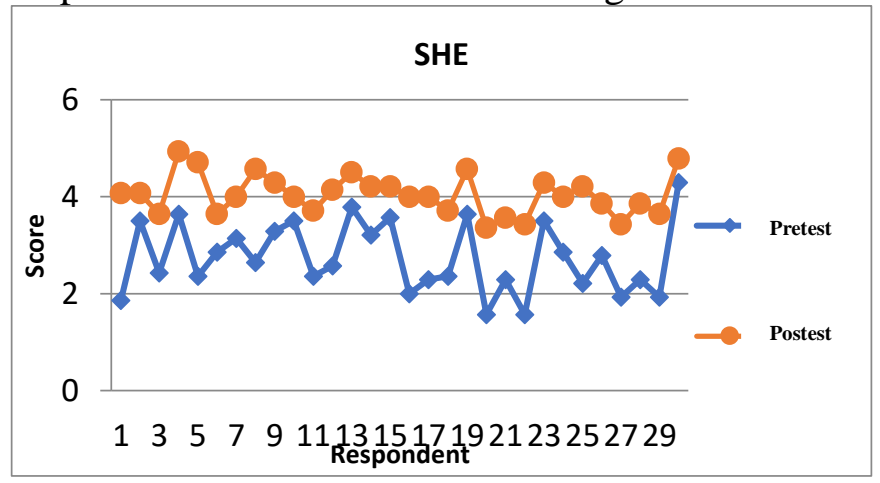

Fig 15. A Chart of Increased Knowledge About Safety and Health Common Respondents Before and After Training 
Test results $t$ to knowledge part human factor and ergonomic hazard got that value sig .( 2-tailed ) as much as $0,000<0.05$, because the value of sig . (2tailed ) smaller of the value of 0.05 so can be concluded that there are differences significantly between knowledge of danger ergonomics of the respondents before and after training work safety and health.

This can also be seen on figure 16 the following which indicates the presence of increased knowledge about danger ergonomics before and after training.

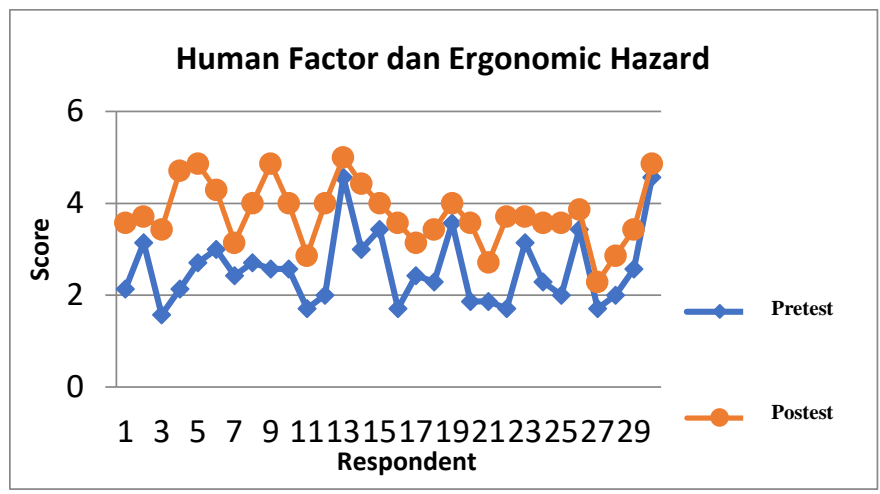

Fig 16. A Chart Increased Knowledge Human Factor and Ergonomic Hazard Before and After Training Work Safety and Health

Testing shows $\mathrm{t}$ on knowledge part danger mechanical sig been gained value .( 2-tailed ) as much as $0,000<0.05$ it, because the value of sig .( 2-tailed ) were less than the value of 0.05 then we can conclude that there is a difference in an ostensible manner between knowledge about the dangers of mechanical before and after training work safety and health.

Figure 17 show an increase knowledge about the dangers of mechanical respondents before and after training.

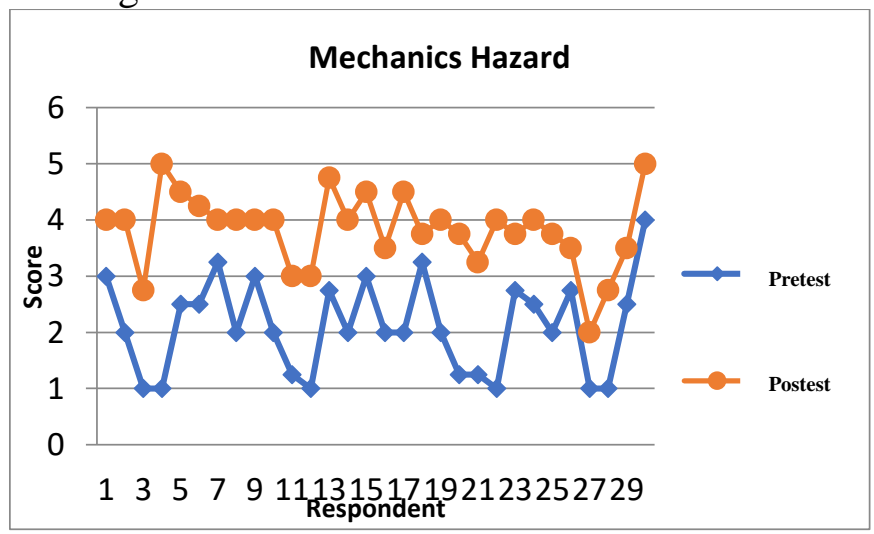

Fig 17. A Chart Increased Knowledge Danger of Mechanical Before and After Training Work Safety and Health
Test results $t$ to knowledge part danger temperature extreme known that the value sig.( 2tailed ) as much as $0,000<0.05$, because the value of sig.(2-tailed ) smaller of the value of 0.05 so can be concluded that there are differences significantly between knowledge of danger temperature extreme before and after training work safety and health. This can also be seen on figure 18 the following which indicates the presence of increased knowledge about danger temperature extreme before and after training.

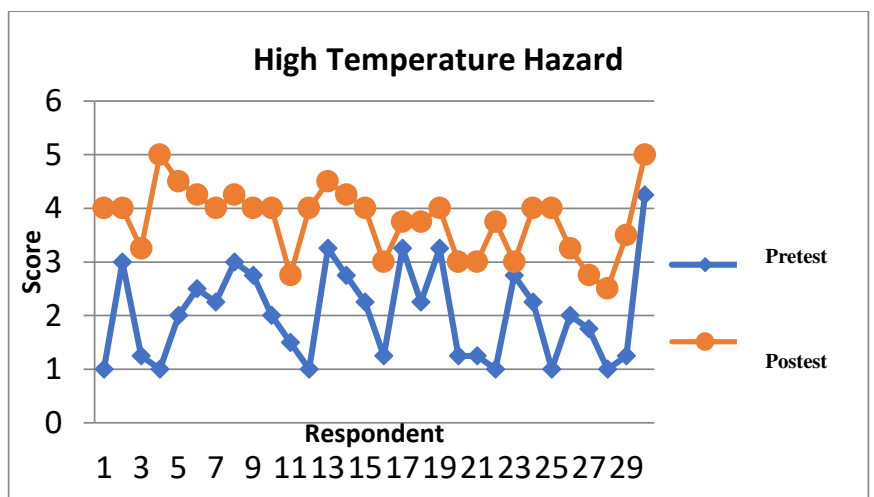

Fig 18. A Chart Increased Knowledge Danger of High Temperature Before and After Training Work Safety and Health

Testing shows $\mathrm{t}$ on knowledge part danger mechanical sig been gained value .( 2-tailed ) as much as $0,000<0.05$ it, because the value of sig .( 2 -tailed ) were less than the value of 0.05 then we can conclude that there is a difference in an ostensible manner between knowledge about the dangers of electrical before and after training work safety and health.

Figure 19 show an increase knowledge about the dangers of electrical respondents before and after training.

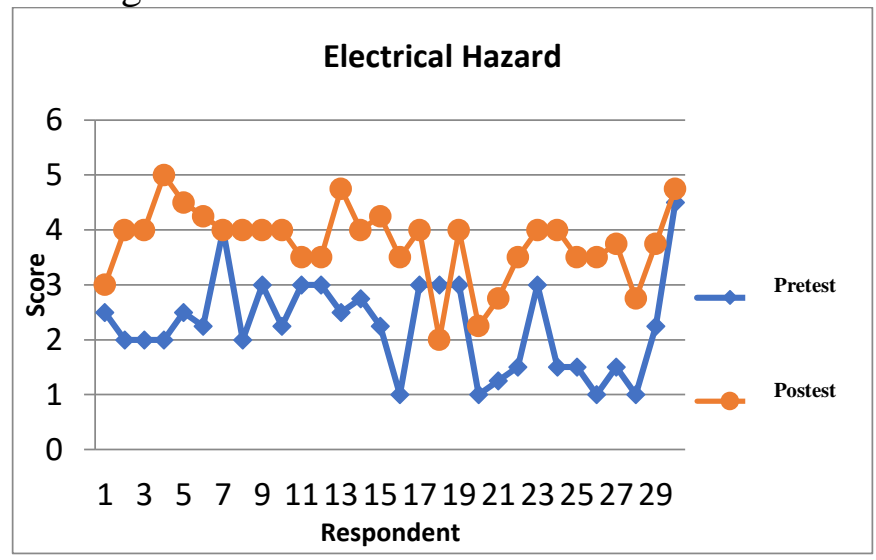

Fig 19. A Chart Increased Knowledge Danger of Electrical Before and After Training Work Safety and Health 
Testing shows $\mathrm{t}$ on knowledge part danger mechanical sig been gained value .( 2-tailed) as much as $0,000<0.05$ it, because the value of sig .( 2-tailed ) were less than the value of 0.05 then we can conclude that there is a difference in an ostensible manner between knowledge about the dangers of fire before and after training work safety and health.

Figure 20 show an increase knowledge about the dangers of fire respondents before and after training.

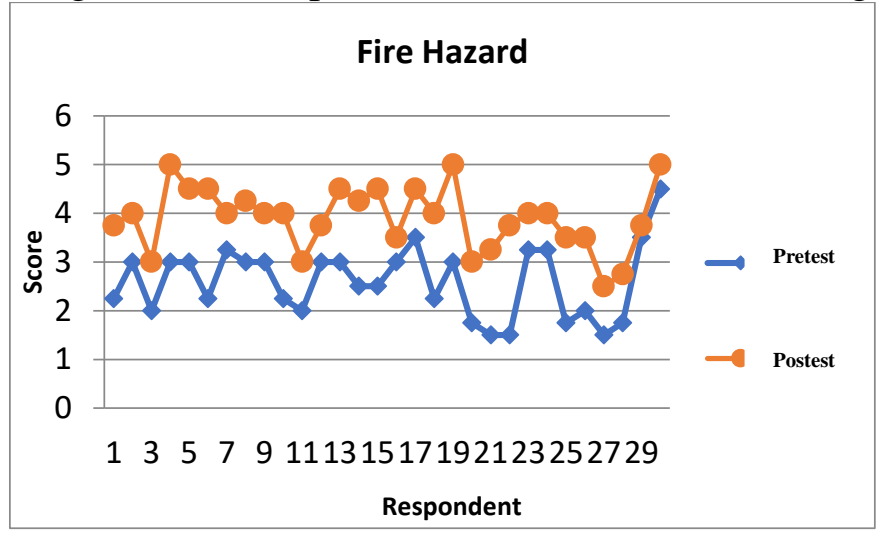

Fig 20. A Chart Increased Knowledge Danger of Fire Before and After Training Work Safety and Health

Testing shows $\mathrm{t}$ on knowledge part danger mechanical sig been gained value .( 2-tailed ) as much as $0,000<0.05$ it, because the value of sig .( 2 -tailed ) were less than the value of 0.05 then we can conclude that there is a difference in an ostensible manner between knowledge about the dangers of noise before and after training work safety and health.

Figure 21 show an increase knowledge about the dangers of noise respondents before and after training.

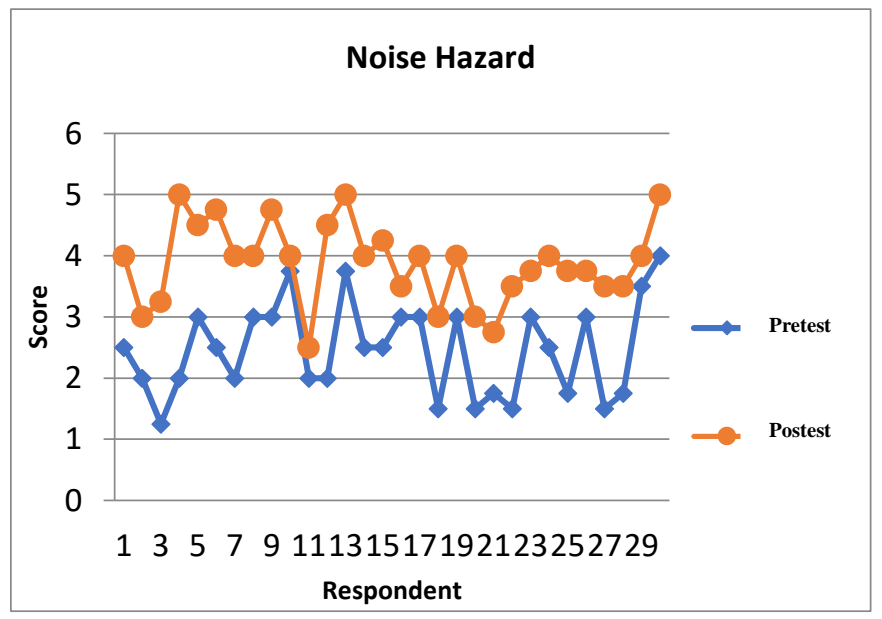

Fig 21. A Chart Increased Knowledge Danger of Noise Before and After Training Work Safety and Health
Testing shows $\mathrm{t}$ on knowledge part danger mechanical sig been gained value .( 2-tailed) as much as $0,000<0.05$ it, because the value of sig.( 2 -tailed ) were less than the value of 0.05 then we can conclude that there is a difference in an ostensible manner between knowledge about the dangers of fall, dropped and fly things before and after training work safety and health.

Figure 22 show an increase knowledge about the dangers of fall, dropped and fly things respondents before and after training.

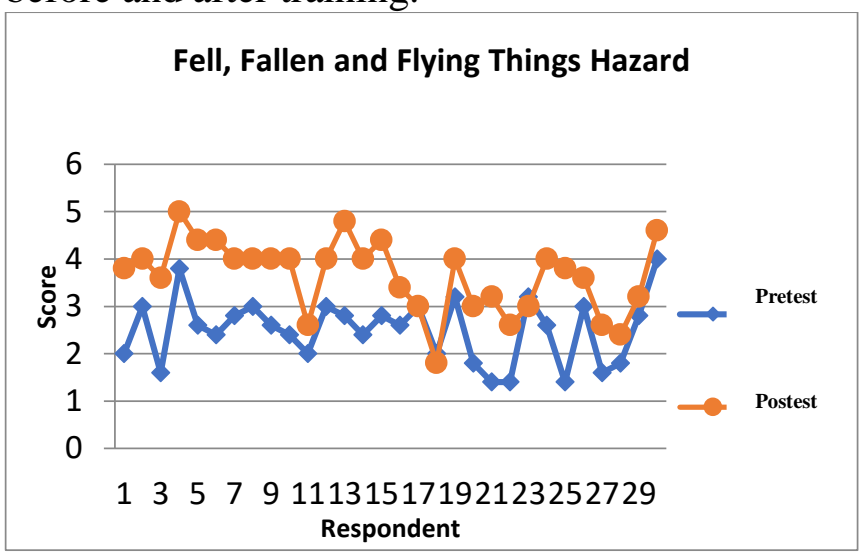

Fig 22. A Chart Increased Knowledge Danger of Fall, Fallen and Flying Things Before and After Training Work Safety and Health

\section{2) The Influence of Occupational Health and Safety Training to Attitude}

From the analysis by using spss 22 get the value of sig . (2-tailed ) of $0,000<0,05$, because the value of sig .( 2-tailed ) smaller than the 0,05 so it can be concluded that there are differences between attitude significantly respondents before and after training work safety and health.

It also is presented in figure 23 the following the show an increase of the respondents before and after training.

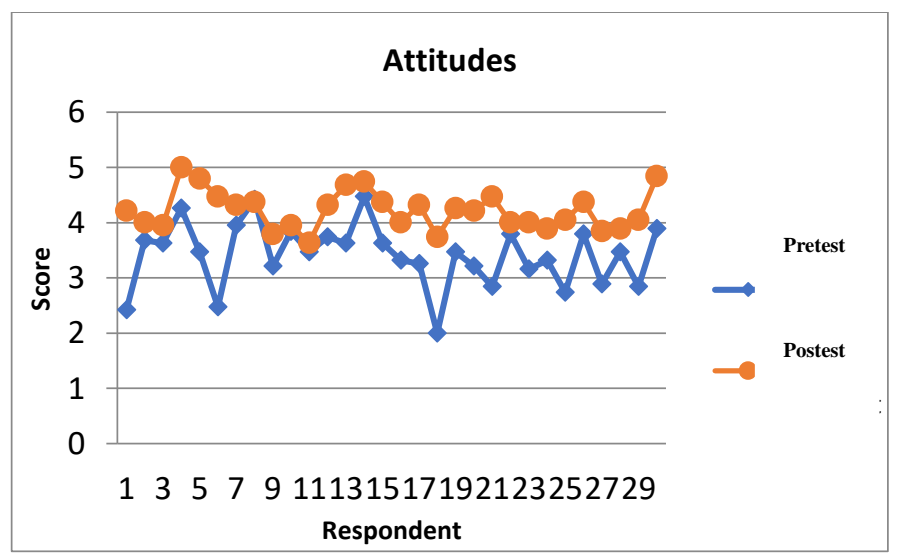

Fig 23. A Chart of Increased Attitude About Safety and Health Common Respondents Before and After Training 
Testing shows $\mathrm{t}$ on knowledge part danger mechanical sig been gained value .( 2-tailed ) as much as $0,000<0.05$ it, because the value of sig .( 2-tailed ) were less than the value of 0.05 then we can conclude that there is a difference in an ostensible manner between attitude about the dangers mechanics before and after training work safety and health.

Figure 24 show an increase attitudes about the dangers of mechanics respondents before and after training.

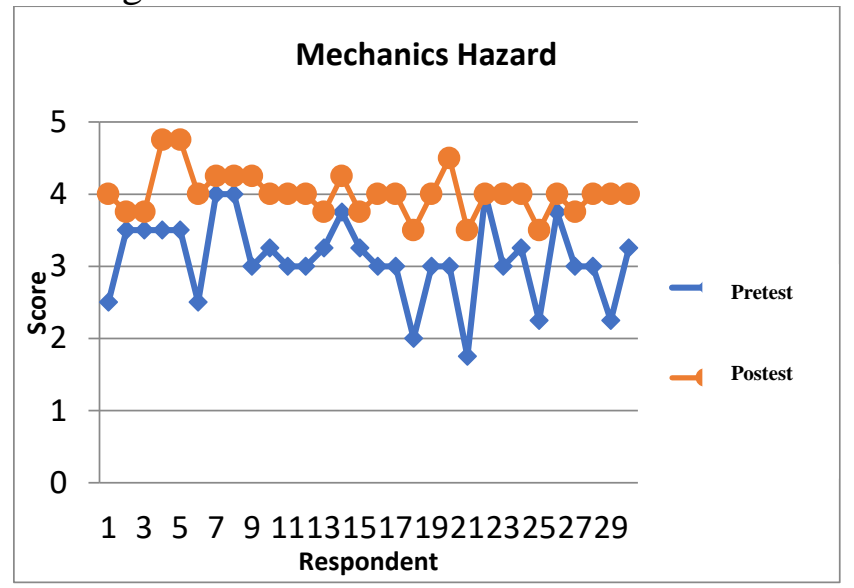

Fig 24. A Chart Increased Attitude Danger of Mechanics Before and After Training Work Safety and Health

Testing shows $\mathrm{t}$ on knowledge part danger mechanical sig been gained value .( 2-tailed ) as much as $0,000<0.05$ it, because the value of sig . (2tailed ) were less than the value of 0.05 then we can conclude that there is a difference in an ostensible manner between attitude about the dangers of high temperature before and after training work safety and health.

Figure 25 show an increase attitude about the dangers of high temperature respondents before and after training.

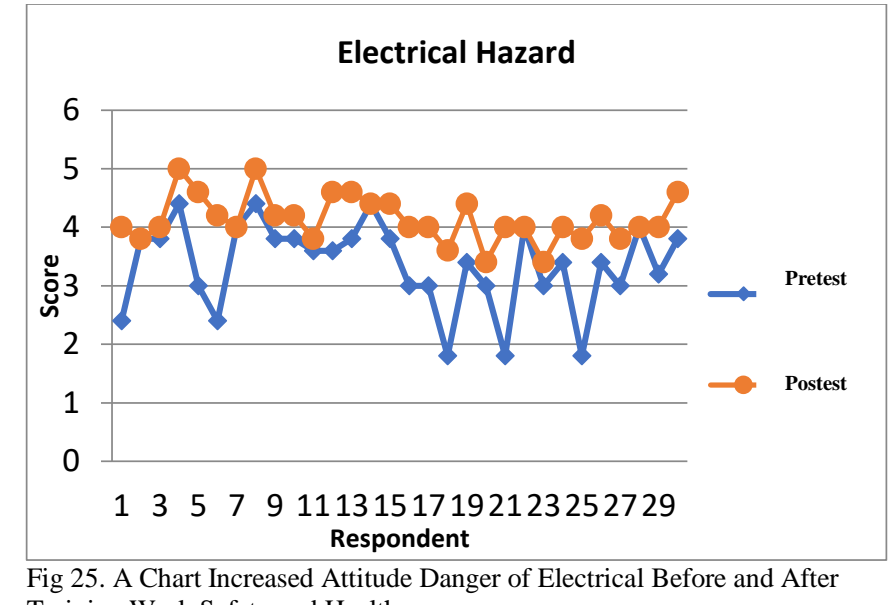

Training Work Safety and Health

Testing shows $\mathrm{t}$ on knowledge part danger mechanical sig been gained value .( 2-tailed ) as much as $0,000<0.05$ it, because the value of sig . (2tailed ) were less than the value of 0.05 then we can conclude that there is a difference in an ostensible manner between attitude about the dangers of fire before and after training work safety and health.

Figure 26 show an increase attitude about the dangers of fire respondents before and after training.

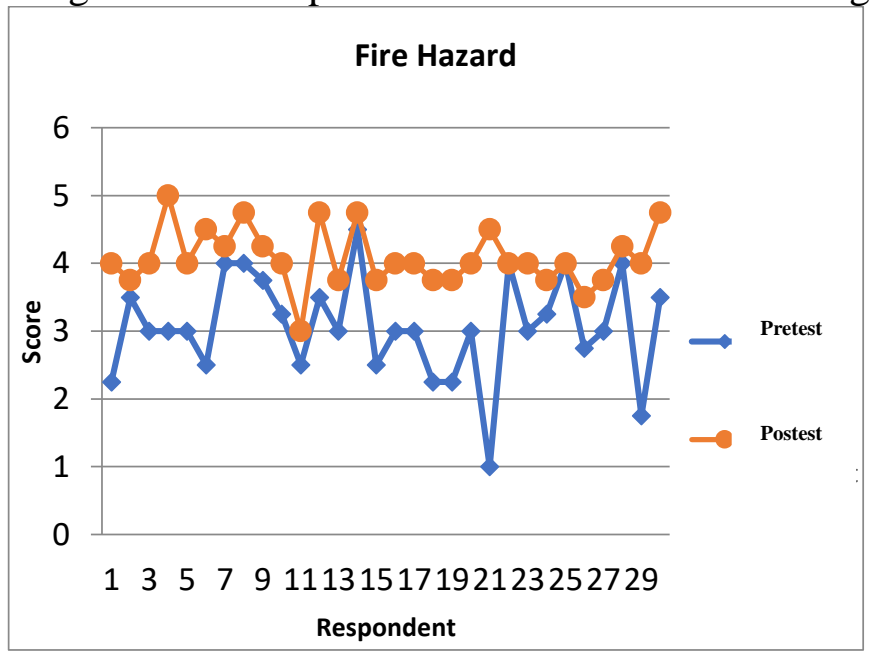

Fig 26. A Chart Increased Attitude Danger of Fire Before and After Training Work Safety and Health

Testing shows $\mathrm{t}$ on knowledge part danger mechanical sig been gained value .( 2-tailed ) as much as $0,000<0.05$ it, because the value of sig . (2tailed ) were less than the value of 0.05 then we can conclude that there is a difference in an ostensible manner between attitude about the dangers of noise before and after training work safety and health. 
Figure 27 show an increase attitude about the dangers of noise respondents before and after training.

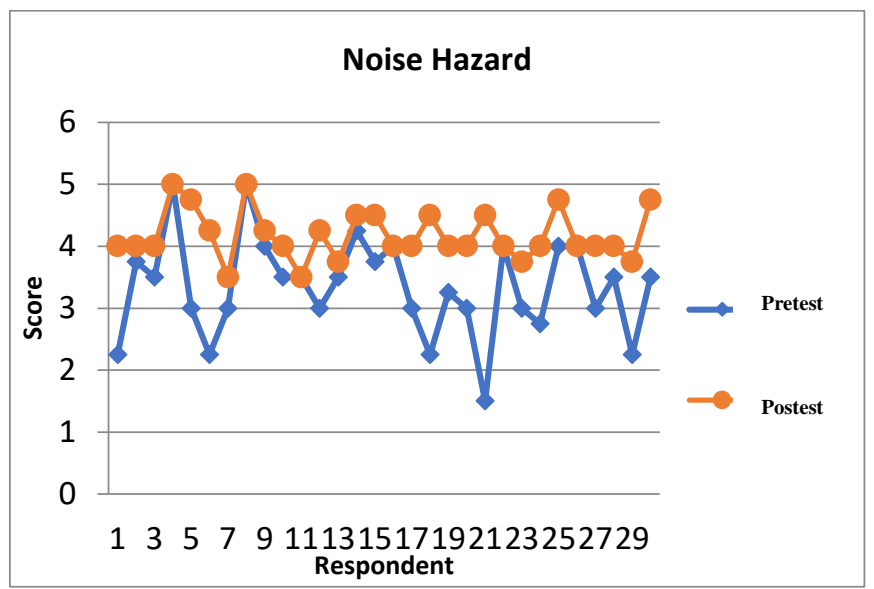

Fig 27. A Chart Increased Attitude Danger of Noise Before and After Training Work Safety and Health

Testing shows $\mathrm{t}$ on knowledge part danger mechanical sig been gained value .( 2-tailed ) as much as $0,000<0.05$ it, because the value of sig . (2tailed ) were less than the value of 0.05 then we can conclude that there is a difference in an ostensible manner between attitude about the dangers of fall, fallen and flying things before and after training work safety and health.

Figure 28 show an increase attitude about the dangers of fall, fallen and flying things respondents before and after training.

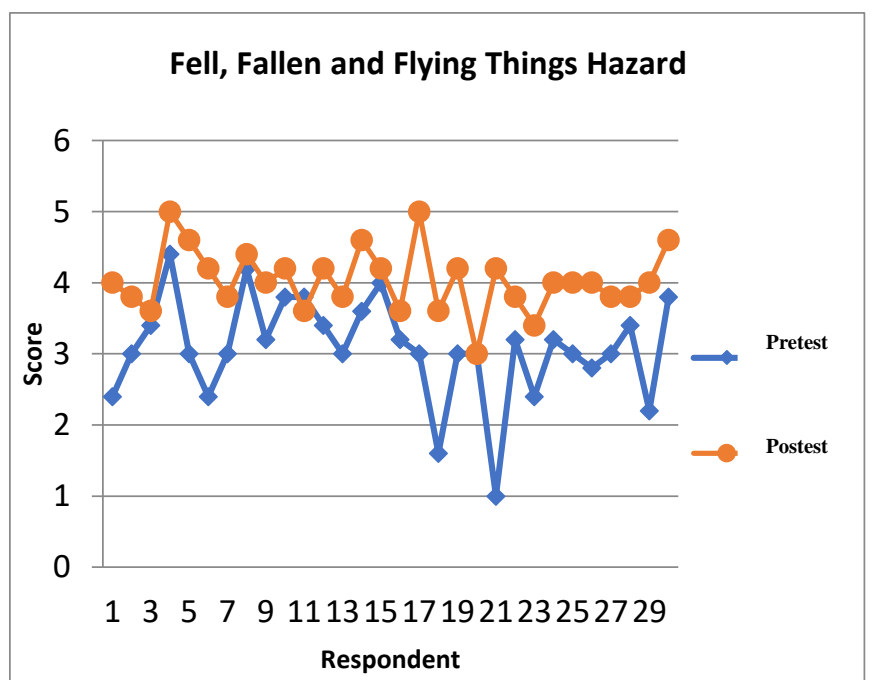

Fig 28. A Chart Increased Attitude Danger of Fall, Fallen and Flying Things Before and After Training Work Safety and Health 3) The Influence of Occupational Health and Safety
Training to Action
From the analysis result of using SPSS 22 got that value sig. ( 2 -tailed ) by $0,000<0.05$ it, because the value of sig. (2-tailed) smaller than the value of 0.05 then we can conclude that there are differences in an unreal manner the act of respondents between before and after training of health and safety. This can also be seen in figure 29 following this that shows the increase in the respondents about attitude part danger of falling, objects fell, and objects thrown off danger scrap before and after training.

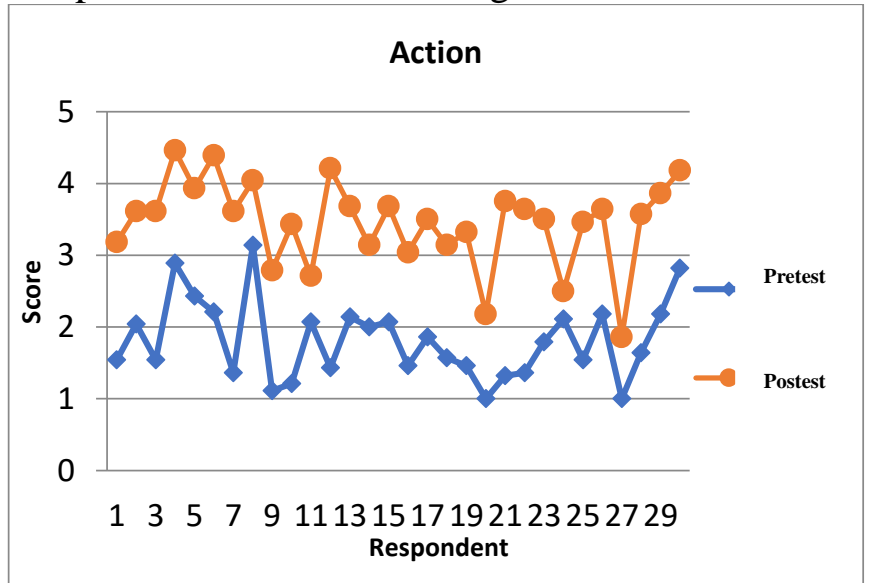

Fig 29. Increasing Graphic The Act of Respondents Before and After Training Work Safety and Health

\section{DISCUSSION}

From the statistical tests using t test to identify the effects organizing training work safety and health of respondents awareness, it is evident that the probability $=0,000 \mathrm{p}$, then $\mathrm{p}<0,05$ of each the question. This shows that there are differences significantly between knowledge was before and after training. Concluded that conducting training on the work safety and health can improve knowledge in the field of work safety and health. The value pretest collected of knowledge safety and health of each question of respondents has a little to work safety and health. This indicates that when unsettled training not work safety and health, obtained implies that respondents has a little know knowledge in the field of work and safety. While value posttest show increase the knowledge of respondents through training work safety and health.

The influence of attitude also shows increase the value of the attitude of respondents after training work safety and health. From the statistical tests using t test to identify the effects organizing training work safety and health of respondents attitude, it is 
evident that the probability $=0,000 \mathrm{p}$, then $\mathrm{p}<0,05$. This shows that there are differences between attitude significantly respondents before and after training.

\section{CONCLUSION}

The conclusions of this research are:

1. Potential danger in the office for each department of engineering faculty of USU are a danger of ergonomics, danger of electrical, danger of noise, danger of fall, objects of fell, objects thrown and danger of scrap, mechanical danger, and the incident, while there aren't chemical danger in office. The most potential danger in office is electrical danger for $26 \%$.

2. Potential danger in manufacturing laboratory in industrial engineering department are danger of mechanics, danger of electrical, danger of fell, fallen and flying things. Otherwise in laboratory of energy conservation in electrical engineering department are danger of mechanics, danger of electrical, danger of fell, fallen and flying things. In laboratory metallurgy in mechanical engineering department are danger of mechanics and electrical. In laboratory chemical research in chemical engineering department are electrical and mechanic dangers. In environmental laboratory in environmental engineering is chemical danger. In concrete laboratory of civil engineering the potential danger is mechanic danger. And the last, in design architecture laboratory potential danger are electrical and ergonomic dangers. The most potential danger in laboratory is electrical danger for $26 \%$

3 . Result of $t$ test is the value of probability $p=0,000$ so $p<0,05$ there is significant relation between lecture and servants knowledge before and after safety and health training.

4. Result of $t$ test is the value of probability $\mathrm{p}=0,000$ so $\mathrm{p}<0,05$ there is significant relation between lecture and servants attitudes before and after safety and health training.

5. Result of $t$ test is the value of probability $p=0,000$ so $p<0,05$ there is significant relation between lecture and servants action before and after safety and health training.
6. Safety sign and procedural book for occupational health and safety are important to prevent accidents and deseaes caused by work.

7. Safety engineering and enviromental health can implemented by OHS training and procuderal book for OHS to prevent accidents and deseaes caused by work.

8. Countiues improvent of Safety engineering and enviromental health, OHS training and procuderal book are important to prevent accidents and deseaes caused by work.

\section{REFERENCES}

[1] Raman Ponniah, dkk. 2016. Counterproductive Work Behavior Among Frontline Government Employees: Role of Personality, Emotional Intelligence, Affectivity, Emotional Labor and Emotional Exhaustion. Malaysia: Universitas Putra Malaysa.

[2] Aschenbrenner, Ann P, dkk. 2016. Nurses' Own Birth Experiences Influence Labor Support Attitudes and Behaviors. AWHOON (Journal).

[3] Ulutasdemir, Nilgun, dkk. 2015. Effects of Occupational Health and Safety on Healthy Lifestyle Behaviors of Workers Employed in A Private Company in Turkey.

[4] Zhu, Andy Yunlong. 2016. The Impact of Organizational Culture on Concurrent Engineering, Design-for-Safety, and Products Safety Performance. China:Goodbaby International Holdings Ltd (Journal).

[5] Pecillo, Malgorzata. 2015. The Resilience Engineering Concept in Enterprise With And Without Occupational Safety and Health Management Systems.

[6] Ulutasdemir, Nilgun, dkk. 2015. Effects of Occupational Health and Safety on Healthy Lifestyle Behaviors of Workers Employed in A Private Company in Turkey.

[7] Bahn, Susanne. 2013. Workplace Hazard Identification and Management: The Case of An Underground Mining Operation. Australia: Eidith University.

[8] Pecillo, Malgorzata. 2015. The Resilience Engineering Concept in Enterprise With And Without Occupational Safety and Health Management Systems.

[9] Babur, Ferhat. 2016. Axiomatic Design for Lean-Oriented Occupational Health and Safety Systems: An Application in Shipbuilding Industry. Turki: Istanbul Electrical University.

[10] Inan, Umut Hulusi, dkk. 2016. A Multiple Attribute Decision Model to Compare The Firms Occupational Health and Safety Management Persectives. Turki: Halic University.

[11] Mirable, Marco. 2014. Workplace Exposure to Engineered Nanomaterials: The Italian Path for The Definition of Occupational Health and Safety Policies.

[12] Nemeth, Erzsebet, dkk. 2009. Fault Diagnosis Based on Hazard Identification Results. Australia: The University of Queensland.

[13] Borowsky Avinoam dan Tal Oron-Gilad. 2013. Exploring The Effects of Driving Experience on Hazard Awareness and Risk Perception Via Real-Time Hazard Identification, Hazard, Classification and Rating Tasks. Israel: Ben-Gurion University. 
[14] Chen Hao, dkk. 2015. Integration of Process Safety Engineering and Fire Protection Engineering for Better Safety Performance. USA: Texas University.

[15] Silva, Marilyn H dan Sheryl L. Beauvais. 2015. Human Health Risk Assesment of Endosulfan, I: Toxicology and Hazard Identification. 